\title{
New Directions for Engaging Patients on Weight Management for General Pediatricians
}

\author{
Matthew A. Broom, MD, FAAP* \\ Gene LaBarge, MD, FAAP \\ Kenneth Haller, MD, FAAP
}

\author{
Address \\ "Department of Pediatrics, Saint Louis University School of Medicine at SSM Cardinal \\ Glennon Children's Medical Center, 1465 S. Grand Blvd, St. Louis, M0 63104, USA \\ Email: broomma@slu.edu
}

Published online: 3 April 2015

C Springer International Publishing AG 2015

This article is part of the Topical Collection on General Pediatrics

Keywords Obesity $\cdot$ Overweight $\cdot$ Text messaging $\cdot$ Motivational interviewing $\cdot$ Social media

\section{Opinion statement}

Successful management of pediatric overweight and obesity remains very challenging, particularly in a busy primary care setting. Numerous barriers exist for both patients and providers. Comprehensive counseling directed at improved dietary habits, increased exercise, and decreased screen time is not always practical. It is crucial to elicit a genuine recognition of the child's obesity as a health problem and obtain a sincere, nonjudgmental commitment to change from the patient as well as parents and other household members. Providers may benefit from learning and utilizing motivational interviewing (MI) as a tool to interact with adolescents and families. In addition, the use of ubiquitous venues such as social media and text messaging, as well as newer health apps may increase continuity and engagement with adolescents and families. Taken together, the traditional modalities of diet, exercise, and screen time counseling, combined with MI and new engagement strategies, such as close follow-up via phone, social media or text provide more opportunities for primary care providers to tighten the belt on the obesity epidemic.

\section{Introduction}

As the battle against child and adolescent obesity has taken center stage, efforts to improve the successful identification, management, and follow-up of pediatric obesity have gotten more prominent. No one is better positioned to make a difference in prevention and treatment than primary care providers. Yet, while general pediatricians have improved their ability to identify children who are overweight or obese, they continue to 
struggle with implementing effective treatment strategies. Given the limited time and community resources available to primary care providers, many have resorted either to referral of patients to tertiary weight management centers or to suboptimal management in the traditional practice setting. Establishing provider-family rapport and building provider-patient continuity are challenging, though critical, elements of a successful therapeutic relationship. Unfortunately, the scattered proximity of weight management centers, poor continuity, long wait times, and lifestyle-change demands on families cause most institutions to have high attrition rates for these patients. This review evaluates the current recommended guidelines for targeted pediatric weight management, examines common barriers that can impede success, explores evolving treatments, and sets an agenda for directed, scalable weight management therapy for the primary care provider in a busy office setting.

\section{Case 1}

Keira is a 6-year-old Black female brought in for her annual well child visit. She is "always hungry." Keira's grandmother has diabetes and her grandfather takes medicine for hyperlipidemia. Keira's body mass index (BMI) is 21 (>99th percentile) and her mother also appears obese. At her last well visit, it was recommended to decrease her daily screen time to less than $2 \mathrm{~h}$ per day, improve her dietary habits with greater attention to fruits and vegetables, and increase her physical activity. Despite this, her weight and BMI have continued to rise. At the current visit, the family appears frustrated by the suggestion that Keira is obese, but they acknowledge that weight has been a problem with several members of the family and inquire about ways to improve weight management.

\section{Case 2}

Sam is a 15-year-old male brought in for an asthma evaluation. He has mild asthma, well controlled on twice daily, low-dose fluticasone. He is concerned about a dirty ring around his neck. At check-in his BMI is noted to be 31 (>99th percentile). When asked about his diet and level of activity, he concedes that he is unhappy with his body image and has been bullied in the past because of his weight. He is frustrated, saying it is difficult for him to exercise, and he does not understand what a "healthy diet" is or whether he is able to afford it. He spends a considerable amount of time each day on his cell phone and home desktop computer. He says that "doctors and skinny people just do not understand what it is like to be heavy." He comments that he wishes there was a program more tailored to him that would help him improve his weight management.

\section{Epidemiology}

Among US youth, nearly $32 \%$ are overweight (BMI between 85th-94th percentile of the sex-specific CDC BMI-for-age growth charts) or obese (BMI $\geq 95$ th percentile) [ $1 \bullet]$. Childhood obesity has more than doubled in children and tripled in adolescents in the past 30 years and has led to a variety of initiatives to improve early identification and management of obesity among children and their families [2, 3]. In 2011-2012, the prevalence of childhood obesity remained at about $17 \%$ for children and adolescents aged 2 to 19 years; steady 
for the past decade $[1 \bullet 4]$. During this time, the prevalence of obesity among children aged 2 to 5 years decreased significantly from 13.9 to $8.4 \%$ but increased among 12 to 19 year olds (20.5\%).

Obesity prevalence among children and adolescents has shown significant racial and age disparities. Prevalence is much higher among Hispanics (22.4\%) and non-Hispanic Black youth (20.2 \%) and lower in non-Hispanic Asian youth $(8.6 \%)$ than in non-Hispanic White youth $(14.1 \%)[1 \bullet]$. Primary care providers must consider ethnic differences and perceptions regarding media use, dietary habits (particularly early in life, including infancy), sleep recommendations, and body image when approaching families about a child's elevated BMI [5]. For the period 1999-2010, obesity prevalence among children whose adult head of household did not complete high school, reflective of a lower socioeconomic status, was approximately twice that of those whose adult head of household completed college ( 19 vs 9 \% among girls; 21 vs $11 \%$ among boys) [6]. Other risk factors for developing childhood overweight include increased parental adiposity, early or more rapid puberty, extreme birth weights, gestational diabetes, and various social and environmental factors, such as childhood diet and time spent in sedentary behaviors [7].

The combined annual health care costs for pediatric and adult obesity exceed US $\$ 190$ billion annually [3]. A number of severe health conditions have been associated with childhood obesity, among them type 2 diabetes mellitus, asthma, sleep apnea, attention deficit hyperactivity disorder, nonalcoholic fatty liver disease, and slipped capital femoral epiphysis $[8,9 \bullet]$. Further, overweight is associated with a higher prevalence of intermediate metabolic consequences and risk factors, such as insulin resistance, elevated blood lipid levels, increased blood pressure, and impaired glucose tolerance. Perhaps the most significant short-term morbidities for overweight/obese children are psychosocial and include social marginalization, decreased self-esteem, and decreased quality of life [7].

\section{Recommended treatments}

In 2010, the US Preventive Services Task Force recommended that children ages 6 to 18 years be screened for obesity by routinely calculating BMI at least annually during health maintenance visits, and if indicated, children should then be referred to programs to improve their weight status [10].

\section{Diet related}

A more recent study has investigated the relationship between early feeding patterns and later obesity in children and adolescents [11]. Breastfeeding in particular has been associated with a number of healthier dietary behaviors at age 6 and may be a protective factor against later child obesity and the chronic diseases that result from it [12]. Frequent bottle emptying and high bottlefeeding intensity during early infancy are associated with 6-year-old children experiencing parental pressure to eat and low satiety responsiveness [13]. 
Further, introduction of sugar-sweetened beverages (SSB), including fruit juices and other artificial beverages and the lack of early introduction of fruits and vegetables in the young child's diet have also been implicated as possible risk factors for obesity in early childhood. SSB intake during infancy significantly increased the likelihood of consuming SSBs at least daily at 6 years of age [14], and children who consumed SSBs during infancy had higher odds of obesity at 6 years than non-SSB consumers [15]. Infrequent intake of fruits and vegetables during late infancy is associated with infrequent intake of these foods at 6 years of age. These findings highlight the importance of infant feeding guidance that encourages intake of fruits and vegetables and the need to examine barriers to fruit and vegetable intake during infancy [13].

As a resource for the general public, the American Academy of Pediatrics (AAP) highlights specific nutrition and caloric recommendations for children based on age on its website [16]. Other key dietary recommendations focus on both social and societal aspects of eating, including maintaining scheduled family meal times (i.e., sitting down at a table together for a meal), not skipping breakfast, awareness of recommended portion sizes, limiting fast food intake, and encouraging food preparation to occur within the home environment [8].

\section{Exercise}

The AAP Council on Sports Medicine and Fitness and Council on School Health has made a number of exercise recommendations for children as a means to lessen risk of overweight (Table 1) [17].

\section{Screen time}

The AAP recommends that parents limit the amount of total entertainment screen time to $<1$ to $2 \mathrm{~h}$ per day, discourage screen media exposure for children $<2$ years of age, keep TV sets and Internet-connected electronic devices out of the child's bedroom, monitor what media their children are using and accessing, including any Web sites they are visiting and social media sites they may be using (Table 2) [18].

\section{Barriers}

Treatment recommendations focus on a staged method based on the child's BMI and comorbidities, which range from primary preventative measures to aggressive multidisciplinary intervention [8].

\section{Patient-centered barriers}

\section{Food access and deserts}

Food access is defined as the proximity of individuals to retailers of nutrient-rich foods, such as fresh fruits and vegetables. Areas with insufficient affordable access to these nutrient-rich foods are known as food deserts, and in the USA, they are most likely to occur in predominantly lower-income neighborhoods and communities [19]. They tend to occur in urban and rural areas in predominantly Black or Hispanic populations. Although the Dietary Guidelines for Americans recommends children greater than 2 years of age should increase their consumption of fruits and vegetables, whole fruit and vegetable consumption 


\section{Table 1. AAP exercise recommendations for children}

- Physical activity should be promoted at home, in the community, and at school, but school is perhaps the most encompassing way for all children to benefit

- Recess can serve as a counterbalance to sedentary time and contribute to the recommended

- Parents should become good role models by increasing their own level of physical activity

- Schools should also provide $1 \mathrm{~h}$ of quality physical education daily to all students in grades K-12

- Physical education should emphasize enjoyable participation in physical activities that help students develop the knowledge, attitudes, motor skills, behavioral skills, and confidence required to adopt and maintain healthy active lifestyles

- Physical education classes should allow participation by all children regardless of ability, illness and/or injury, including those with obesity and those who are disinterested in traditional competitive team sports

- Parents of overweight children and youth need to play a supporting, accepting, and encouraging role in returning them to healthier lifestyles to increase self-esteem

- Whether schools provide such activity or not, all children should engage in at least $1 \mathrm{~h}$ of physical activity a day

remains well below recommended levels [20]. Depending on one's region and focus of practice, primary care providers may meet considerable challenges in patients' physical access to healthy foods.

\section{Cost}

Unfortunately, the costs of nutrient-rich foods often exceed high-calorie foods with lower nutritional value and this chasm has only widened over the past decade [21]. As a result, for families with limited budgets, unhealthy fast food or pre-packaged food choices have become favorable financial alternatives [22].

\section{Availability of and access to exercise venues}

Though schools are charged with providing a minimum of 60 min daily of exercise for youth, this is not always the case. Additionally, among some urban and suburban environments, there are few opportunities for safe, outside exercise. Community exercise facilities (e.g., parks and YMCA) often do not extend into the inner city, creating significant disparities between resources available to urban children. This emerges as a key reason among many families for not encouraging outside activity.

\section{Table 2. AAP recommendations on screen time and media for children}

- Limit the amount of total entertainment screen time to $<1$ to $2 \mathrm{~h}$ per day

- Discourage screen media exposure for children $<2$ years of age

- Keep the TV set and Internet-connected electronic devices out of the child's bedroom

- Monitor what media their children are using and accessing, including any Web sites they are visiting and social media sites they may be using

- Co-view TV, movies, and videos with children and teenagers, and use this as a way of discussing important family values

- Model active parenting by establishing a family home use plan for all media

- As part of the plan, enforce a mealtime and bedtime "curfew" for media devices, including cell phones

- Establish reasonable but firm rules about cell phones, texting, Internet, and social media use 


\section{Motivation to change}

A principle component of motivational interviewing (MI) (discussed below) is assessing readiness for change in a patient. The patient must recognize an inherent conflict between one's specific behavior pattern and their goals. If this conflict is not recognized, the patient and family may be unaware or in denial of a medical condition. Without this awareness or willingness to explore therapeutic options related to their health, change is less likely to occur.

The reasons behind patient lack of awareness or unwillingness to change are difficult to delineate and vary significantly. Embedded within the obesity epidemic are complicated factors relating to familial and cultural backgrounds. Some of these differences are perceived to contribute to the obesity epidemic and may limit patient readiness to change [23, 24]. For example, a child whose parent is obese is significantly more likely to develop obesity than the child of a normal-weight parent [25]. Multigenerational obesity thereby increases the difficulty of raising a family's awareness of and willingness to change. Other cultural presuppositions may be influential as well, for example, the notion that a heavier infant may be viewed as healthier in certain cultural settings [23].

\section{Provider-centered barriers}

\section{Time}

Nearly $80 \%$ of preventative medicine visits are 20 min or less [26]. During each visit, the provider must assess diet, sleep, patient safety, oral health, mental health, chronic medical conditions, and family health and wellness [27]. The provider also performs a physical examination, assesses immunization and laboratory needs, and provides patient-directed anticipatory guidance. With limited time, providers may perceive there to be little to no positive impact in providing patient education [28].

\section{Evolving knowledge and evidence}

The childhood obesity epidemic is well known, but successful, reproducible management strategies applicable to the primary care provider have not been as clearly described. As a result, many providers complete training and are in practice without a clear understanding of the most up-to-date published peerreviewed guidelines [24]. Finally, given the busy schedule of a primary care physician, it can be daunting to remain current on the most effective methods of prevention and treatment. As a result, providers may be hesitant to address the issue of obesity if they have no clear idea of how to treat it.

\section{Available resources and staff}

Depending on a physician's time and comfort level as well as the staging of obesity management, a patient may benefit from multidisciplinary or subspecialty care [8]. However, with up to 12 million or more children who are overweight or obese, it is not feasible for multidisciplinary sites to provide universal care for these individuals. Depending on the region and patient population, providers and patients may have limited access to these multidisciplinary clinics or subspecialists [29]. The AAP has worked to provide billing guidance and resources for primary care providers to help practices be 
appropriately reimbursed for the time and staff investment related to their weight management services [8]. Despite this, consideration is required for new methods of engagement with patients and families as an effort to narrow the divide between current practice recommendations and actual patient outcomes.

\section{New treatment options}

Three evolving methods of therapy for obesity are reviewed below: MI, text messaging, and social media. All share in one common thread: increasing patient engagement via closer provider-patient interaction. These tools are not stand-alone therapies, yet they represent powerful adjunct therapies that may directly appeal to adolescents (or their parents), improve engagement and motivation regarding their own weight management, and retain applicability for the pediatric primary care provider.

Motivational interviewing (MI) is an evidence-proven method for behavioral change, having its roots in substance-abuse counseling [30, 31]. MI is an encouraging, nonjudgmental style of counseling that holds the provider as a guide, empowering the patient to reflect, verbalize, and take action on their own regarding targeted behaviors [8]. Practitioners use open-ended, reflective questions or statements (e.g., "Tell me more about that," "I understand that you would like to exercise more. What would that look like for you?"). These help patients identify personal values and assist with reconciling current behavior with their stated goals.

Though there has been a fair amount of work evaluating the place of MI as a tool for health-related behavioral change with adults, particularly with favorable results for obesity, not as much emphasis has been placed on children and adolescents $[32,33]$. The AAP has created the Institute for Healthy Childhood Weight and developed a tool to teach MI to primary care providers in order to better engage patients and families on obesity [34•]. This tool allows for primary care providers to receive CME credit while utilizing a Web-enabled program to teach basic skills in MI. Live courses, even those of short duration, may also provide a foundation with which to begin exercising MI in a busy office environment.

There is growing interest in broadening the use of health information technology to improve the weight management of overweight and obese adolescents [35••]. Text messaging has become a ubiquitous form of communication in American teenagers [36]. Seventy-five percent of teenagers own a cellular telephone, and almost $90 \%$ use text messaging. Adolescents aged 14-17 send and receive on average about 181 text messages per day (median 100) and $87 \%$ of adolescents in this age group report owning a cell phone [37, 38].

Text messaging as an adjunctive weight loss intervention among adults has led to decreases in weight and increases in healthy behaviors [39-41]. Adolescents are the largest users in the USA of texting, and people who are overweight 
or obese are more likely to access their cellular phones on a daily basis [42]. Despite the ready opportunity to engage adolescents and the growing problem of childhood obesity, there are limited data regarding use of text messaging to improve health-related behaviors in this population [35••].

In order to increase the likelihood of successful, sustained communication between obese adolescents and their medical providers, we must understand the types and frequency of messages that would be most salient within the targeted demographic [43]. Some investigators have begun to evaluate the use of text messages as an adjunct to multidisciplinary adolescent weight management [44]. Teens were enthusiastic about receiving messages that were helpful, positive, encouraging, motivational, or informative. They enjoyed specific content that educated them on healthy diet choices and contained recommendations regarding specific recipes.

Within a busy office practice, the most practical texting programs would be fully automated and administered by a third party. Many platforms are available to primary care physicians, some of which can provide appointment reminders via text. Practice considerations include determining what level of detail to provide via text, HIPAA compliance, whether to accept responses, and what guidance to provide patients and families regarding the timing of an expected response if two-way texting is enabled.

Physician offices may alternatively choose to utilize evolving educational platforms as a method to distribute information to a group of subscribers via text message [45]. Programs like Remind ${ }^{\odot}$ are free, protect the receiver's identity, and provide quick, reliable one-way text messages. Messages can be scheduled months in advance, and users may control their own level of access. These programs can push out health-related (non-HIPAA) content to a wide audience via the comfort of anonymity for the recipient.

Overall, automated text messaging as an adjunct therapy has demonstrated promise as a tool for weight management among adolescents, bridging contact between visits, aiding with appointment reminders, and providing ongoing patient education at a low cost.

Social media is an endemic form of interaction among adolescents [46, 47]. There is a rapidly growing body of research on the use of social networks to enact health-related behavioral change [48]. Given teenagers' preoccupation with interacting via electronic communication or online, utilizing this approach would appear to be present a good opportunity.

Of note Facebook, the most popular social networking platform [49], has been evaluated among overweight and obese college-aged students as a remote weight management intervention, with content tailored over time by a health coach [50]. Barriers included the variability of users' interactions and slow disengagement from the program over time. Issues surrounding privacy, particularly with regard to weight management among teenagers require significant oversight, input, and consent from their parent(s) as social media is not without risk. Bullying can become a major issue and quickly spin out of control, often unbeknownst to parents, caregivers, and teachers. Practice social media sites should be proctored daily for any content that is not consistent with the mission of the site. 
Some practices may also choose to utilize Twitter and post generalizable health-related content for their patients, families, staff, and colleagues. Twitter offers a shortened format ( $<140$ characters), allows for anyone to follow and provides a great way to provide basic medical opinions or information. Physicians who use Twitter professionally should maintain strict, non-HIPAA interactions with their followers, establishing clear guidelines and expectations regarding rules for use with a practice's patient population.

\section{Other technologies}

Other burgeoning technologies may aid the pediatrician working with obese patients. Smartphone applications like MyFitnessPal ${ }^{\odot}$ help users log calories and exercise. Devices like FitBit ${ }^{\circledR}$ and Apple Watch ${ }^{\odot}$ assist users in monitoring physical activity and vital signs. Apple's latest operating system (iOS 8) comes standard with a personalized health application, allowing users to enter details about their health, nutrition, fitness, sleep, lab results, vital signs, and body measurements. These mobile options can actively engage tech-savvy teens in self-monitoring of dietary intake and physical activity.

\section{Case 1 follow-up}

Keira's exam is significant for obesity and mild tonsillar hypertrophy, but is otherwise unremarkable. Your next appointment is a few minutes late and has not yet been triaged. You ask in a nonjudgmental style about perceptions and barriers regarding weight management, and learn that Keira lives in an urban neighborhood without easy access to safe exercise venues. Additionally, Keira eats a lot of fast food because her family has limited access to fruits and vegetables, primarily due to cost and lack of availability. And though Keira does not watch television much, she spends three or more hours per day playing games on her mother's tablet.

Using MI techniques, you find yourself mildly optimistic that this family is ready for change. You encourage them to commit to two focused changes of their choice. They elect to (1) go for daily $20+$ minute chaperoned walks with Keira in the neighborhood, and (2) place a lockout timer for Keira on the tablet, allowing $1 \mathrm{~h}$ on school days and $2 \mathrm{~h}$ on weekend days. Keira is not thrilled about the tablet restriction, but is excited about going for walks with her grandmother and agrees with the plan. They schedule a follow-up appointment in 1 month. As they leave, you recognize the benefit of further modifications to Keira's lifestyle but understand that Keira and her family are more likely to be successful by implementing their own ideas and achieving some initial victories as a foundation for long-term change.

Sam is obese, and his skin is notable for acanthosis nigricans and abdominal striae. The rest of his exam is unremarkable. You discuss with Sam programs and other ways to learn about a healthy diet and how to exercise, and he appears interested. Sam and his mother have considered the multidisciplinary weight management clinic at the nearby university, and you make a referral on his behalf. While this is good news, you recognize that many of your referrals to the 


\section{Conclusions}

weight management program never actually have set foot in the clinic, so you push the discussion and offer more information. Sam uploads MyFitnessPal ${ }^{\odot}$ while you are talking to him in the examination room, and he expresses a willingness to track his physical activity throughout the week. He also enrolls in a Remind ${ }^{\odot}$ program which offers motivational and informational texts related to weight management. You, Sam, and his mother talk briefly about healthy choices, including recognition of the benefits in eating meals together when possible. You remind Sam of his strengths and that changes occur in small steps. He and his mother agree to return in 1 month for follow-up.

The work that pediatric providers must do to address childhood and adolescent obesity is daunting. This is especially true for those primary care providers whose patients and families may have little access to weight management programs or services at tertiary pediatric medical centers. Developing a community-aware, patient- and family centered model of pediatric weight management based within a primary care practice is critical for the successful management of overweight and obese youth (Fig. 1). Within this model, several items are clear:

- Early intervention, in the form of vigorous promotion of breast feeding, elimination or at least reduction in the use of sugar-sweetened beverages for young children, promotion of family exercise, and minimizing

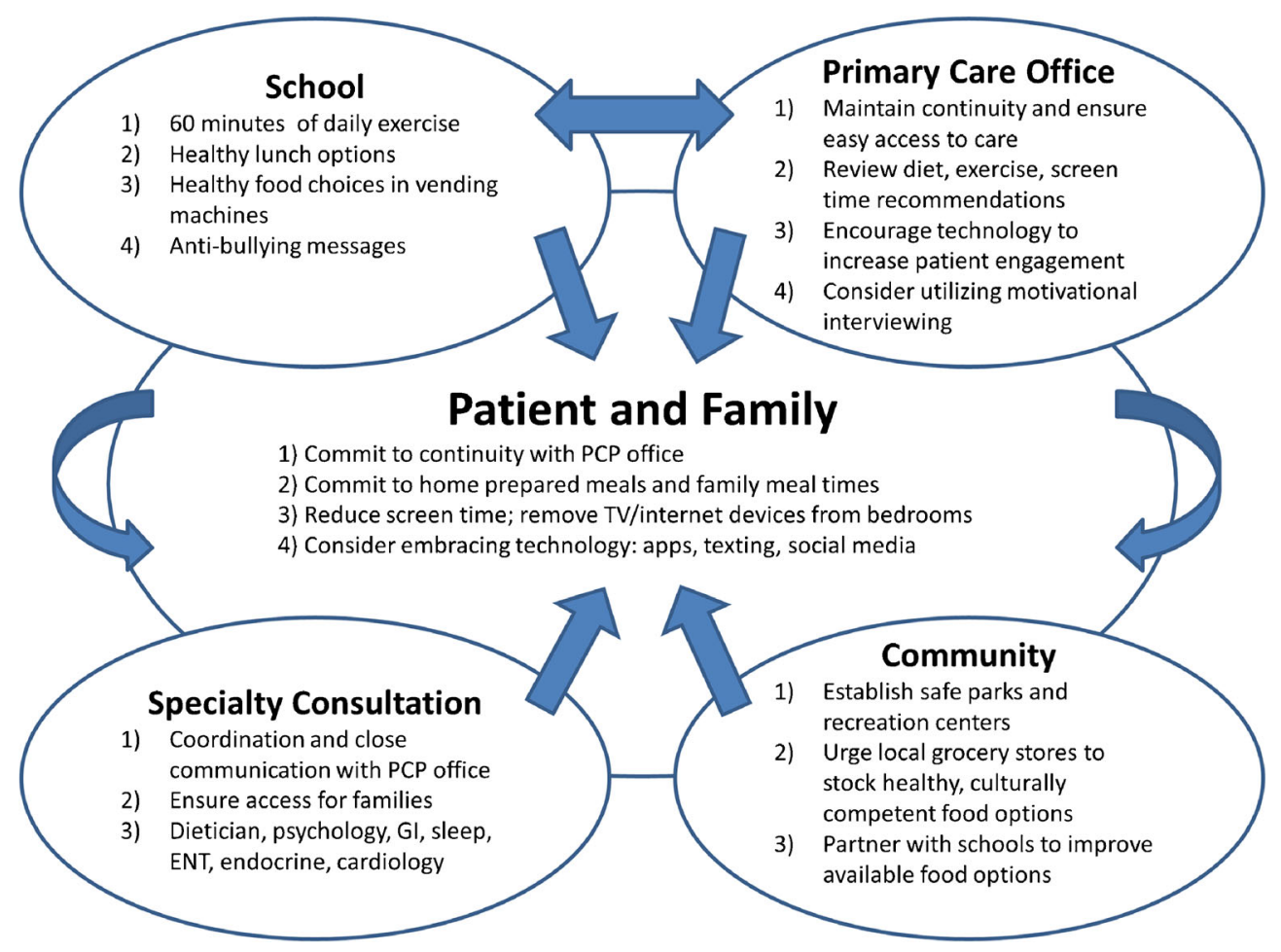

Fig. 1. Patient and family centered model of pediatric weight management. 
screen time for children, will have the downstream effect of maximizing the possibility of a childhood free from obesity.

- Successful, sustainable weight management cannot be accomplished without a clear commitment from both patient and family that this is a problem they need to address as a family unit.

- While a multidisciplinary approach is optimal, finding creative avenues for children and families to exercise and engage in healthy food choices is possible for community-based primary care practitioners.

- A willingness to embrace new technologies like social media, text messaging, smartphone applications, and wearable monitoring devices may provide more "bang for the buck" for the community-based physician and assist them in engaging a tech-savvy generation.

- Childhood and adolescent obesity remains an evolving field within the clinical practice of pediatrics and will continue to provide primary care providers the ability to engage in research opportunities affecting future management and advancing the field with creative, innovative, patient and family centered approaches.

\section{Compliance with Ethics Guidelines}

\section{Conflict of Interest}

Matthew A. Broom has received the Fleur de Lis Grant from SSM Cardinal Glennon Foundation during the conduct of the study and grants from Maternal, Child \& Family Health Coalition outside the submitted work. Gene LaBarge declares that he has no conflict of interest.

Kenneth Haller declares that he has no conflict of interest.

Human and Animal Rights and Informed Consent

This article does not contain any studies with human or animal subjects performed by any of the authors.

\section{References and Recommended Reading}

Papers of particular interest, published recently, have been highlighted as:

- Of importance

$\bullet$ Of major importance

1.• Ogden CL, Carroll MD, Kit BK, Flegal KM. Prevalence of childhood and adult obesity in the United States, 2011-2012. JAMA. 2014;311(8):806-14.

This article summarizes the most recent childhood and adult obesity prevalence data and trends in the United States.

2. Let's move. 2011. http://www.letsmove.gov/. Accessed 6 Oct 2014.

3. Institute of medicine. Accelerating progress in obesity prevention: solving the weight of the nation. Washington DC: National Academies Press; 2012. http://
www.iom.edu/Reports/2012/Accelerating-Progress-inObesity-Prevention.aspx. Accessed 6 Oct 2014.

4. Ogden CL, Carroll MD, Kit BK, Flegal KM. Prevalence of obesity and trends in body mass index among US children and adolescents, 1999-2010. JAMA. 2012;307(5):483-90.

5. Pena MM, Dixon B, Taveras EM. Are you talking to ME? The importance of ethnicity and culture in childhood obesity prevention and management. Child Obes (Print). 2012;8(1):23-7. 
6. Centers for Disease Control and Prevention. Obesity-United States, 1999-2010. MMWR. Morbidity and mortality weekly report. 2013;62(3):120128. Accessed 8 Oct 2014

7. Whitlock EP, Williams SB, Gold R, Smith PR, Shipman SA. Screening and interventions for childhood overweight: a summary of evidence for the US Preventive Services Task Force. Pediatrics. 2005;116(1):e125-44.

8. Barlow SE. Expert committee recommendations regarding the prevention, assessment, and treatment of child and adolescent overweight and obesity: summary report. Pediatrics. 2007;120 Suppl 4:S164-92.

9.• Kelly AS, Barlow SE, Rao G, et al. Severe obesity in children and adolescents: identification, associated health risks, and treatment approaches: a scientific statement from the American Heart Association. Circulation. 2013;128(15):1689-712.

This article provides a comprehensive review of the morbidities associated with child and adolescent obesity along with an indepth summary of the current recommendations for medical and surgical treatments.

10. Barton M. Screening for obesity in children and adolescents: US Preventive Services Task Force recommendation statement. Pediatrics. 2010;125(2):361-7.

11. Krebs NF, Jacobson MS. Prevention of pediatric overweight and obesity. Pediatrics. 2003;112(2):424-30.

12. Perrine CG, Galuska DA, Thompson FE, Scanlon KS. Breastfeeding duration is associated with child diet at 6 years. Pediatrics. 2014;134 Suppl 1:S50-5.

13. Li R, Scanlon KS, May A, Rose C, Birch L. Bottle-feeding practices during early infancy and eating behaviors at 6 years of age. Pediatrics. 2014;134 Suppl 1:S70-7.

14. Park S, Pan L, Sherry B, Li R. The association of sugarsweetened beverage intake during infancy with sugarsweetened beverage intake at 6 years of age. Pediatrics 2014;134 Suppl 1:S56-62.

15. Pan L, Li R, Park S, Galuska DA, Sherry B, Freedman DS. A longitudinal analysis of sugar-sweetened beverage intake in infancy and obesity at 6 years. Pediatrics. 2014;134 Suppl 1:S29-35.

16. American Academy of Pediatrics. Childhood nutrition. 2014. http://www.healthychildren.org/English/ healthy-living/nutrition/Pages/Childhood-Nutrition. aspx. Accessed 8 Oct 2014.

17. Active healthy living: prevention of childhood obesity through increased physical activity. Pediatrics. 2006;117(5):1834-1842.

18. Council on Communications Media. Children, adolescents, and the media. Pediatrics. 2013;132(5):958-61.

19. Institute of Medicine and National Research Council. The public health effects of food deserts: workshop summary. Washington: National Academies Press; 2009.

20. U.S. Department of Agriculture and U.S. Department of Health and Human Services. Dietary guidelines for
Americans. 7th ed. Washington, DC: U.S. Government Printing Office; 2010.

21. Drewnowski A. The cost of US foods as related to their nutritive value. Am J Clin Nutr. 2010;92(5):1181-8.

22. Monsivais P, Aggarwal A, Drewnowski A. Following federal guidelines to increase nutrient consumption may lead to higher food costs for consumers. Health Aff. 2011;30(8):1471-7.

23. Hughes CC, Gooze RA, Finkelstein DM, Whitaker RC. Barriers to obesity prevention in head start. Health Aff. 2010;29(3):454-62.

24. Spivack JG, Swietlik M, Alessandrini E, Faith MS. Primary care providers' knowledge, practices, and perceived barriers to the treatment and prevention of childhood obesity. Obesity (Silver Spring). 2010;18(7):1341-7.

25. Semmler C, Ashcroft J, van Jaarsveld CH, Carnell S, Wardle J. Development of overweight in children in relation to parental weight and socioeconomic status. Obesity (Silver Spring). 2009;17(4):814-20.

26. Halfon N, Stevens GD, Larson K, Olson LM. Duration of a well-child visit: association with content, familycenteredness, and satisfaction. Pediatrics.

2011;128(4):657-64.

27. Hagan JF, Shaw JS, Duncan PM, editors. Bright futures: guidelines for health supervision of infants, children, and adolescents. 3rd ed. Elk Grove Village: American Academy of Pediatrics; 2008.

28. Klein JD, Sesselberg TS, Johnson MS, et al. Adoption of body mass index guidelines for screening and counseling in pediatric practice. Pediatrics. 2010;125(2):265-72.

29. Walsh CO, Milliren CE, Feldman HA, Taveras EM. Factors affecting subspecialty referrals by pediatric primary care providers for children with obesity-related comorbidities. Clin Pediatr Phila. 2013;52(8):777-85.

30. Prochaska JO, Velicer WF. The transtheoretical model of health behavior change. Am J Health Promot. 1997; 12(1):38-48.

31. Miller W, Rollnick S. Motivational interviewing: preparing people to change addictive behavior. New York: Guilford Press; 1991.

32. Armstrong MJ, Mottershead TA, Ronksley PE, Sigal RJ, Campbell TS, Hemmelgarn BR. Motivational interviewing to improve weight loss in overweight and/ or obese patients: a systematic review and meta-analysis of randomized controlled trials. Obes Rev. 2011;12(9):709-23.

33. Britt E, Hudson SM, Blampied NM. Motivational interviewing in health settings: a review. Patient Educ Couns. 2004;53(2):147-55.

34. American Academy of Pediatrics. Change talk: childhood obesity. 2014. http://www.kognito.com/ changetalk/web/.

Outstanding web reference and resource for primary care providers to learn and practice basic tools of motivational interviewing in the context of pediatric obesity.

35.• Smith AJ, Skow Á, Bodurtha J, Kinra S. Health information technology in screening and treatment of child 
obesity: a systematic review. Pediatrics. 2013;131(3):e894-902.

Comprehensive analysis of current research investigating outcomes on the use of health information technology (telemedicine, text messaging, etc.) as treatments for child obesity.

36. Terry M. Text messaging in healthcare: the elephant knocking at the door. Telemed J E Health. 2008;14(6):520-4.

37. Resnicow K, McMaster F, Woolford S, et al. Study design and baseline description of the BMI2 trial: reducing paediatric obesity in primary care practices. Pediatr Obes. 2012;7(1):3-15.

38. Schwartz RP, Hamre R, Dietz WH, et al. Office-based motivational interviewing to prevent childhood obesity: a feasibility study. Arch Pediatr Adolesc Med. 2007;161(5):495-501.

39. Patrick K, Raab F, Adams MA, et al. A text messagebased intervention for weight loss: randomized controlled trial. J Med Internet Res. 2009;11(1):e1.

40. Haapala I, Barengo NC, Biggs S, Surakka L, Manninen P. Weight loss by mobile phone: a 1year effectiveness study. Public Health Nutr. 2009;12(12):2382-91.

41. Gerber BS, Stolley MR, Thompson AL, Sharp LK, Fitzgibbon ML. Mobile phone text messaging to promote healthy behaviors and weight loss maintenance: a feasibility study. Health Informatics J.

2009;15(1):17-25.
42. Fjeldsoe BS, Marshall AL, Miller YD. Behavior change interventions delivered by mobile telephone shortmessage service. Am J Prev Med. 2009;36(2):165-73.

43. National Cancer Institute. Making health communication programs work. U. S. Department of Health \& Human Services. 2008. http://cancer.gov/cancertopics/ cancerlibrary/pinkbook/Pink_Book.pdf.

44. Woolford SJ, Clark SJ, Strecher VJ, Resnicow K. Tailored mobile phone text messages as an adjunct to obesity treatment for adolescents. J Telemed Telecare. 2010;16(8):458-61.

45. Baker M. Tech tools for training. T+D. 2014;68(7):28.

46. Lenhart A. Teens, smartphones \& texting. Washington, DC: Pew Research Center; 2012.

47. Lenhart A. Teens, cell phones and texting: text messaging becomes centerpiece communication. Washington, DC: Pew Research Center; 2011.

48. Maher CA, Lewis LK, Ferrar K, Marshall S, De Bourdeaudhuij I, Vandelanotte C. Are health behavior change interventions that use online social networks effective? A systematic review. J Med Internet Res. 2014;16(2):e40.

49. Duggan M, Smith A. Social media update 2013. 2013. http://www.pewinternet.org/2013/12/30/socialmedia-update-2013/. Accessed 4 Aug 2014.

50. Merchant G, Weibel N, Patrick K, et al. Click "like" to change your behavior: a mixed methods study of college students' exposure to and engagement with Facebook content designed for weight loss. J Med Internet Res. 2014;16(6):e158. 